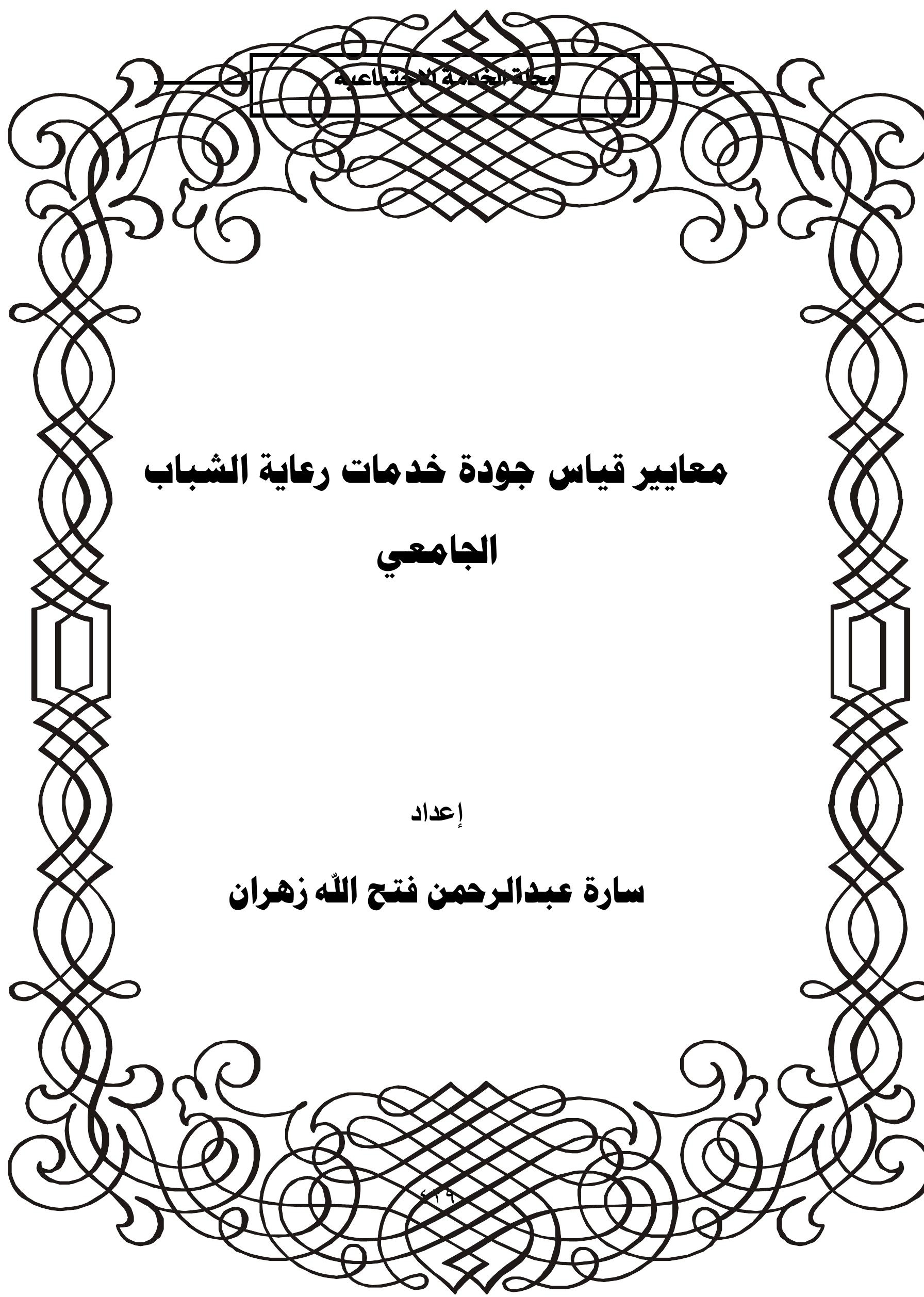




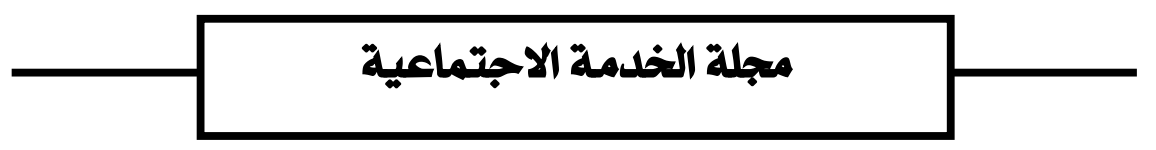

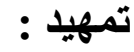

تمثل جودة العمل مركز اهتمام الديانات السماوية عبر التاريخ والتي تعد منهجا

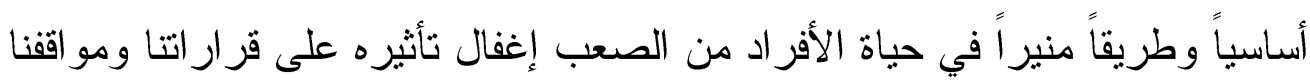
التربوية و لذا وجب عرض لمحة من كتاب الله عز وجل لفهم القاعدة الأساسية

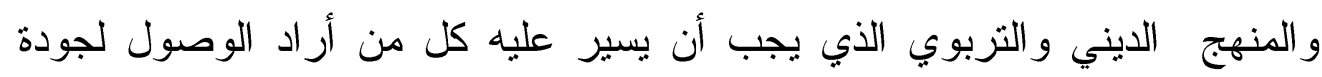
الأداء الشخصي أو المؤسسي.

فلقد حث ديننا الحنيف على الإتقان والإخلاص في العمل كمدخل لبناء مجتمع قوى

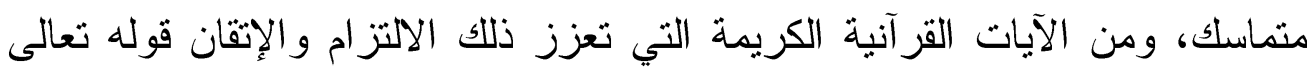

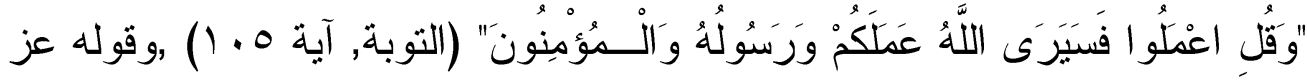

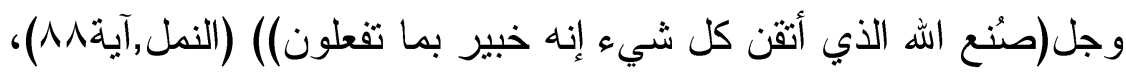

وقوله سبحانه (( إن الذين آهنوا وعملوا الصالحات إنا لا نضيع أجر من أحسن

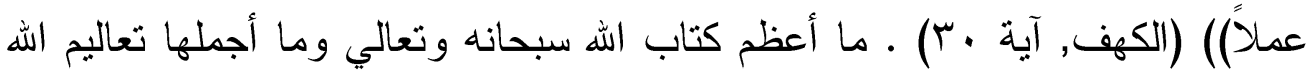

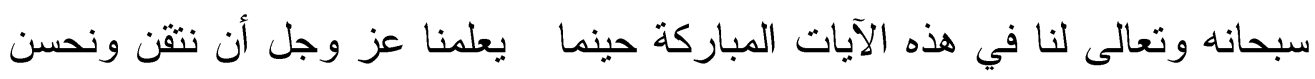

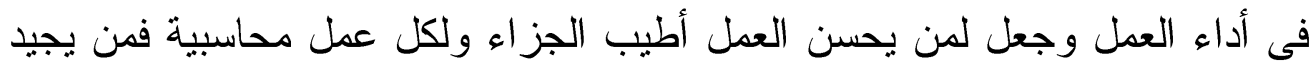
ويحسن يكافأ, ومن خلال التفحص لرؤية الإسلام من خلال الأحاديث النبوية الناء

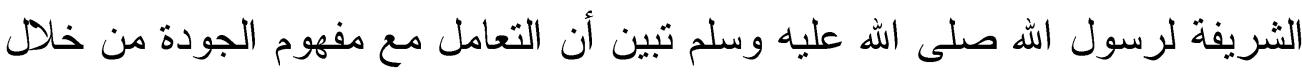

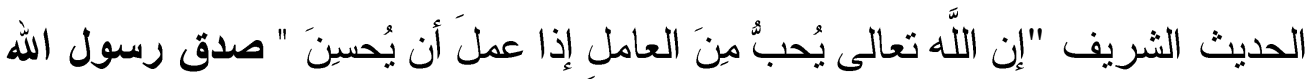

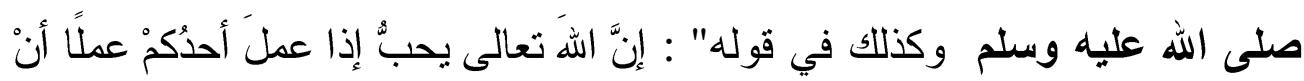

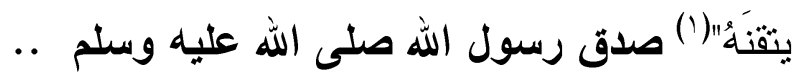

و على ضوء ما سبق من آيات قر آنية مباركة و أحاديث نبوية شريفة نجد أن الإسلام وضعنا على الطريق السليم لتطبيق الجودة والتي تعنى حب العمل و الإتقان في أدائه على الرغم من أنه لم تذكر كلمة الجودة صريحة ولكن عبر عنها بالإثقان الجنان 'ـــ كليب الجهني المحدث :السيوطي_المصدر الجامع الصغير ,الصفحة أو الرقم: 1862 , نسخه الكترونيه , موسوعة 


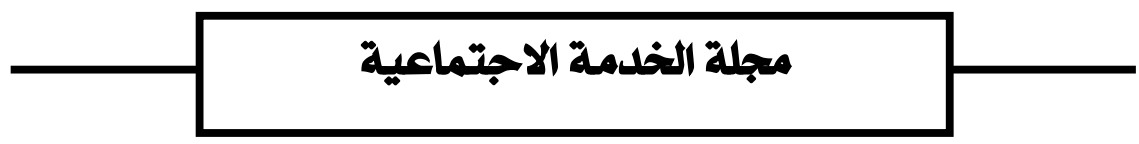

في العمل والإحسان فيه, والباحث في إدارة الجودة الثاملة يجد أنها" احتلت مكانة الصدارة في تفكير الاقتصاديين و التزبويين لتحسين نوعية التعليم بكافة مستوياته وفي

جميع أبعاده و عناصر ه،" (1)

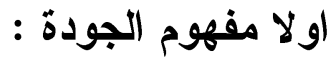

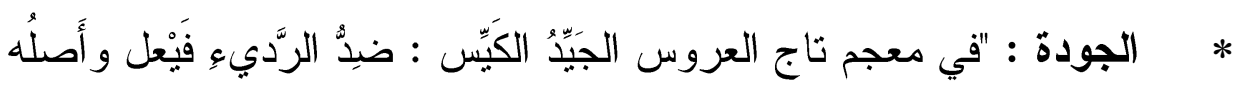

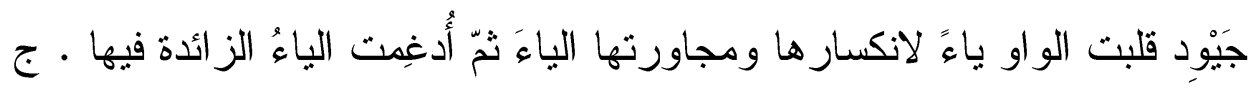

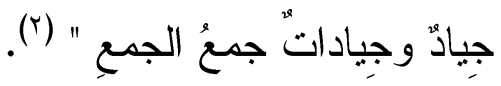

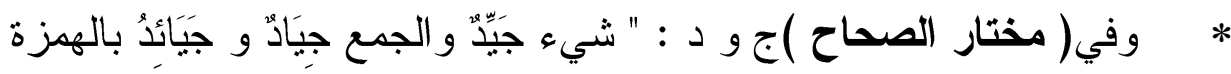

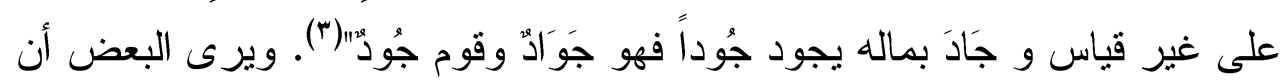
الجودة هي إتقان وسلامة من العيوب، بينما ير اها البعض تحقيق الثيء للهدف منه

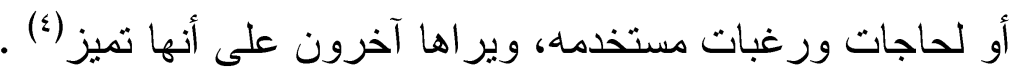

كما تعرف بانها بكونها تكامل الملامح و الخصائص لمنتج أو لخدمة بصورة ما

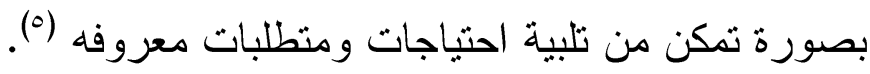

\section{1- الجودة الثاملة :}

" هي عملية إدارية تزتكز على مجموعة من القيم تستمد طاقة حركتها من المعلومات التي نتمكن في إطار ها من استثمار قدر ات العاملين الفكرية في مختلف

ـ ـ محد بن شحات الخطيب نحو هيئة وطنية للاعتماد الأكاديمي للتعليم العالي في المملكة العربية السعودية، الرياض:

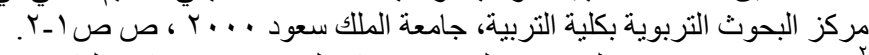

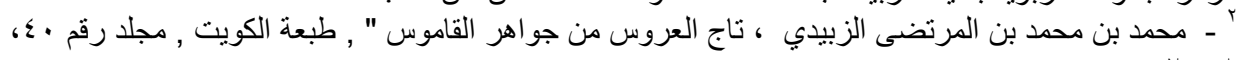

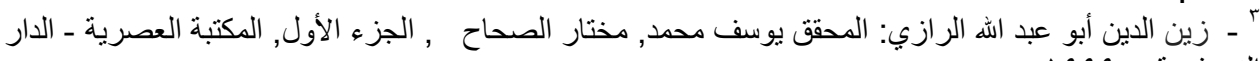
4 -Harvey L. and Green D:( Defining quality. Assessment and Evaluation in Higher Education, vol, 18. 1993,p 19

• محمد عبدالغني : مهار ات ادارة الاداء ، معايير وتطبيقات ادارة الجودة في الاداء ،القاهره، مركز تطوير الاداء

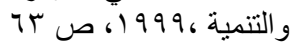




\section{مجلة الخدمة الاجتماعية}

مستويات التتظيم على نحو إبداعي لتحقيق التحسن المستمر "('), كما تعرف الجودة الشاملة بأنها "طريقة لإدارة المؤسسة تهدف إلي التعاون و المشاركة الفعالة من كل

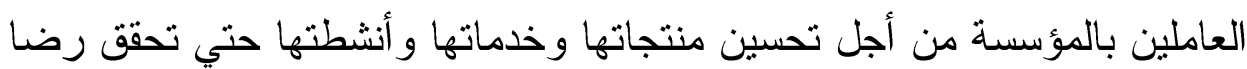
العملاء , و أهداف المؤسسة لمصلحة الجميع وما يتفق مع متطلبات المجتمع"(r) . و هي فلسفة إدارية حديثة ، تأخذ شكل أو نهج أو نظام إداري شامل قائم على أساس إحداث تغيير ات إيجابية جذرية لكل شيء داخل المؤسسة ، بحيث تشمل هذه التغيير ات: الفكر السلوك القيم الأداء المعتقدات التظظيمية و المفاهيم الإدارية ، نمط القيادة الإدارية ، ونظم و إجر اءات العمل و غير ها" (").

كما وتعرف أيضاً بانها" طريقة الإدارة بالمؤسسة التي تهدف إلى التعاون

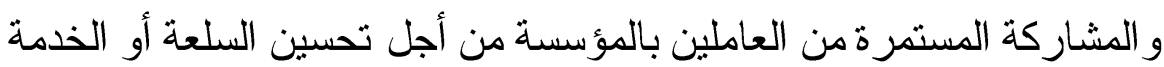

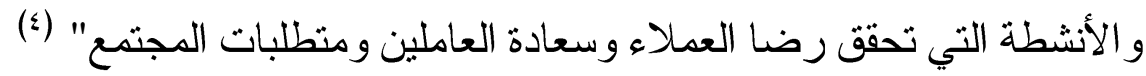

\section{r- جودة خدمات الرعاية الاجتماعية :}

\section{أ- خدمات الرعاية الاجتماعية :}

تعرف بانها الأنشطة المنظمة للمؤسسات الأهلية أو الحكومية والتي تسهم في

إثباع الحاجة و المساهمة في حل المشكلات الاجتماعية أو تحسين الأحوال الاجتماعبة للأفر اد أو الجماعات و المجتمات و هذه الأنشطة تتضدن جهود مختلفة

المهنيين كالأطباء و الممرضين و القانونيين و الأخصائيين الاجتماعيين (०).

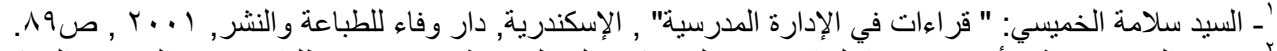

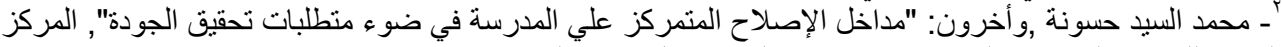

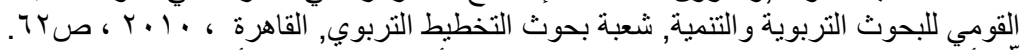

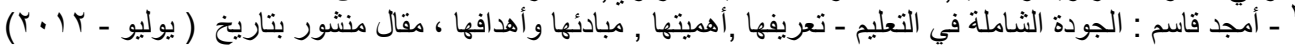

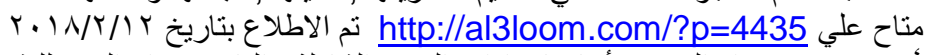

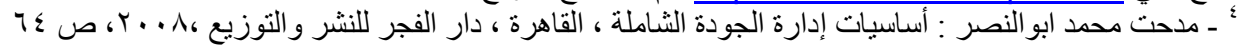
5 - Ruth Edunkle : Protective for children, encolopedia of social work, N.Y, National association of social workers, 1981, P.744 . 


\section{مجلة الخدمة الاجتماعية}

وتعرف أيضا على أنها خدمات منظمة وأن المؤسسات التي تقدم هذه الخدمات

تتمتع ببنية رسمية وتحكم أنشطتها قو اعد ومعايير تتظيمية , و لا تقاس خدمات ونهات الرعاية الاجتماعية بمقياس مادى ملموس فإشباع حاجات الناس المتتوعة وتتمية

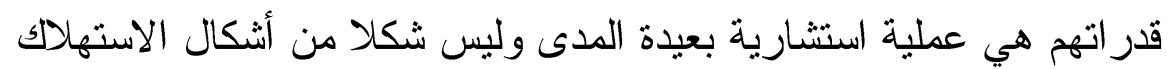
المادي(') . و تعرف خدمات الرعاية الاجتماعية على أنها " مجموعة من الأنشطة

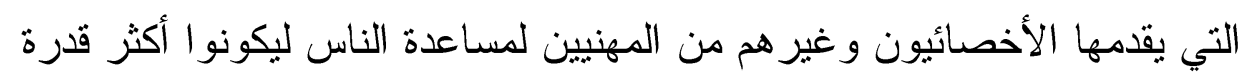

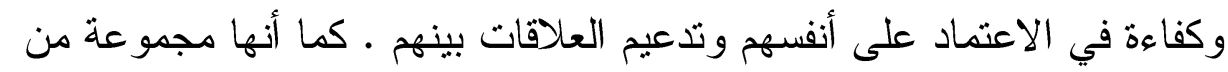
البر امج و الإجر اءات التي بستخدمها الأخصائيون أي أصحاب المهنة المرتبطة بهر و الموجه نحو أهداف الرعاية الاجنماعية (r).

وتعرف جودة الخدمة علي أنها : تلك الجودة الــني تشمل على البعد الإجرائـي

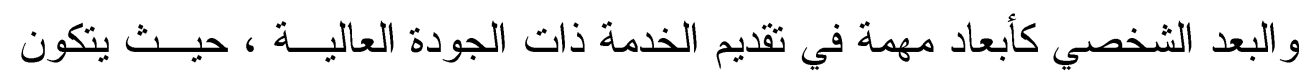
الجانب الإجر ائي من النظم والإجر اءات المحددة لتقديم الخدمة أما الجانب الثخصي

للخدمــة فهــو كيف يتفاعل العاملون (بمواقفه وسلوكياتهم وممارساتهر اللفظية)

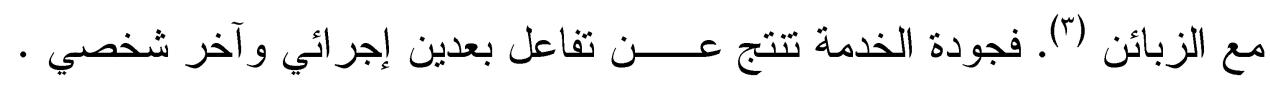
حيث يكمل الأول الثاني فحين ينطلب الثاني الأول .

أما عن جودة خدمات الرعاية الاجتماعية فهي تعبر عن مقياس للارجة التي تزتثي بها الخدمات ،لتقابل توقعات العملاء إذن هي مدى تطابق توقعات الزبائن مع الخدمة المقدمة فعلا من قبل مقدم الخدمة (£) . ثانياً: مفهوم الثباب الجامعي :

'ـ خليل درويش ,و ائل مسعود : مدخل إلى الخدمة الاجتماعية , القاهرة , الثركة العربية المتحدة للتسويق و التوريدات ,

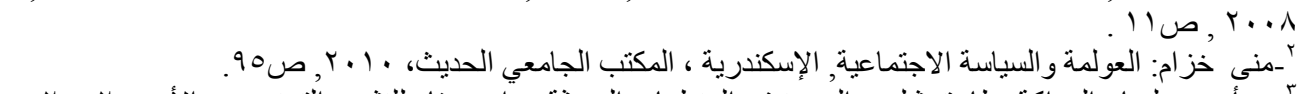

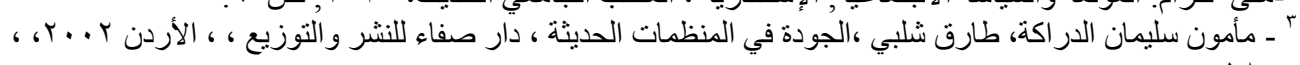
ص11.

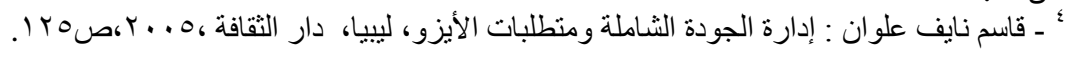




\section{مجلة الخدمة الاجتماعية}

الشباب هو جمع مذكر ومؤنث معاً، وتعني الفتاء و الحداثة، ويطلق لفظ شبان،

وشبيبة، كجمع لمذكر مفرد شاب، ويطلق لفظ شابات، وشائب، وشو اب، كجمع

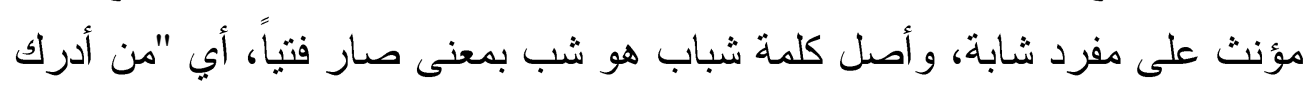
سن البلوغ ولم يصل إلى سن الرجولة"(1).

ويعرف الشباب لغويا فيقال : شاب الغلام شبابا ادرك طور الشباب (؟)، و يعرفه معجم وبستر Webster بانه فتره من الحياه تقع ما بين مرحله الطفولة مرحله

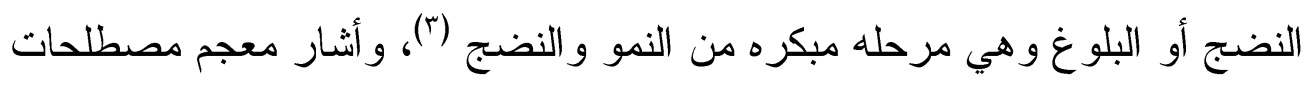
العلوم الاجتماعية إلى أن الثباب مرحله انتقاليه إلى الرجولة أو الأمومة ويتخطى ونى

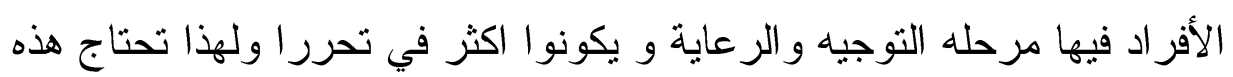

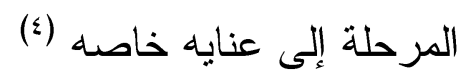

أما في معجم Oxford فإن لفظ الشباب يقابله باللغة الإنجليزية كل من

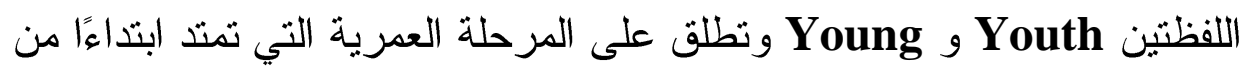
مرحلة الطفولة إلى ما قبل الرشد (0). ويعرف الثباب من الناحية البيولوجية بانه تلك المرحلة التي يتم فيها اكتمال البناء العضوي و الوظيفي للمكونات الأساسية للجسم (`). ويعرف الشباب الجامعي بصفه عامه بانهم الأشخاص الذين بدرسون

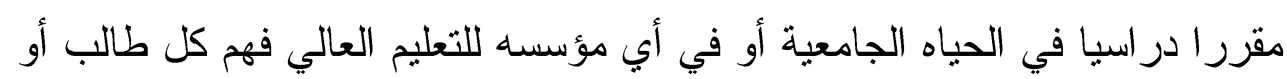

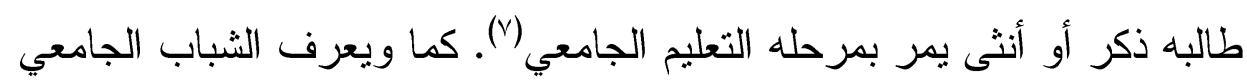
أيضا علي انه كل طالب أو طالبه ذكر ا أو اثثي يمر بمرجلة التعليم الجامعي (^).

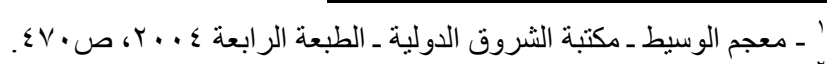

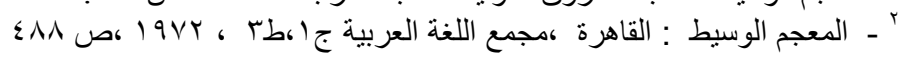

3 - Webster's : world dictionary of American language, N.Y, the world company, 1999,p 169

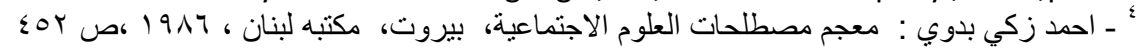

5 - Oxford, Learners Pocket, Dictionary, Fourth edition 2008, p 518.

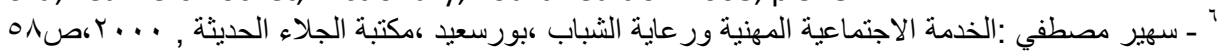

7 - bikpen Doulas: community organization theory and practice , new jersey, prentice hill, pp 186-187

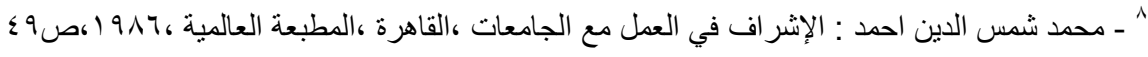




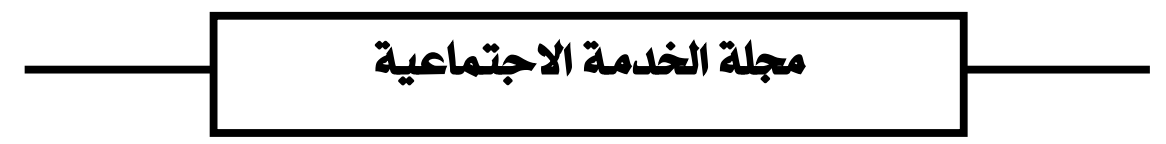

ثالثًا: حاجات ومشكلات الشباب الجامعي:

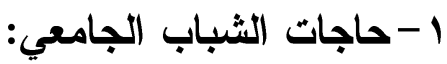

تتعدد حاجات الثباب ومنها ('):

أ. حاجات فسيولوجية: و هي الحاجات الخاصة بالمحافظة على التوازن

الفيسيولوجي الضروري للإنسان منها حاجات الجسم للطعام و الشراب

$$
\text { و غير ها. }
$$

ب. حاجات نفسيه: و منها الحاجه لفه الذات وتقبلها أو حل "ازمه الهوية " وهو يتطلب فهم التغيرات التي تطر ا على كيان الفرد وقبولها و الحصول

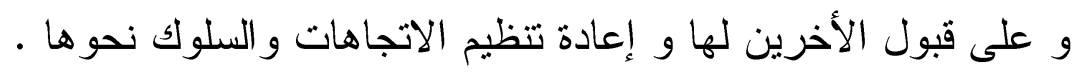
ج. حاجات اجتماعيه : و منها الحاجه إلى الحصول على اعتر اف بتخطي مرحله الطفولة والانتماء إلى جماعات الر اشدين و الحاجة الي الحب .

\section{د - الحاجات الروحية (؟)}

تعتبر الحاجات الروحية مظلة وقاية في إثباع الحاجات الأخرى أن الحاجات

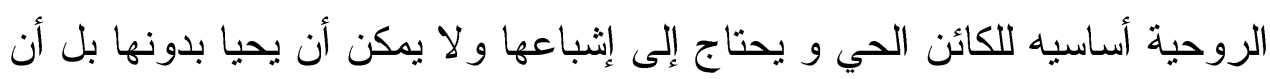

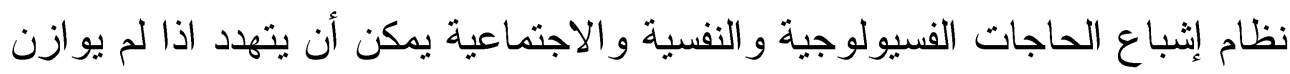
بين إثباع هذه الحاجات وحاجاته الروحية عية

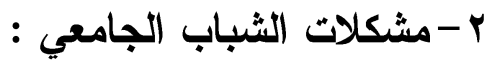
يمكن عرض أهم تلك المشكلات فيما يلي(r):-

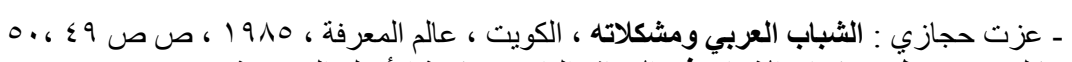

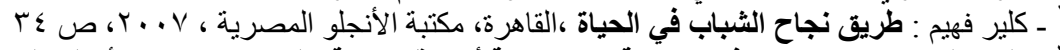

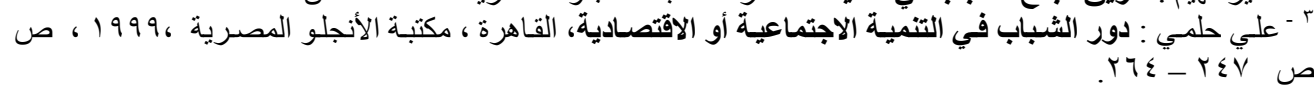




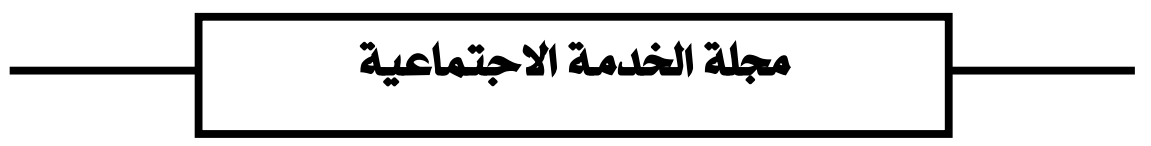

\section{أ. أمشكلات النفسية : المية}

وتتركز معظم المشكلات النفسية للشباب حول مشكلات النمو الانفعالي

لمرحلة المر اهقة والاستعداد للرشد وتحمل المسئولية و الاستقلال وتحمل المسؤولية

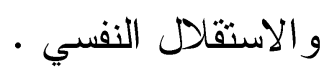

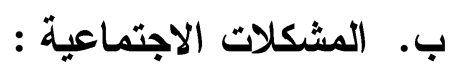

ويتصف هذا الجانب الاجتماعي لاى الثاب بمظاهر رئيسيه إما التآلف مع الآخرين أو النفور منهم وفي حاله التألف قد يميل الشباب إلي الجنس الأخر نتيجة إلي التربية

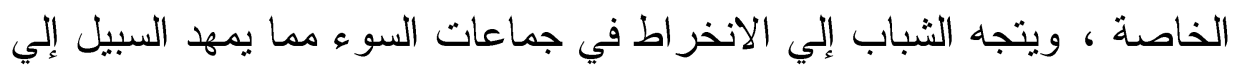
ظهور مشكلات الانحر افات السلوكية كالسرقة وارتكاب الجر ائم و الغش في في الغي

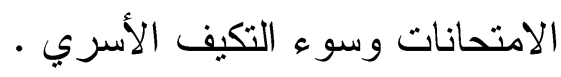

ج (الإدمان

ويحدث الإدمان في عالم الخمور و المسكر ات و المخدرات و العقاقير المخدرة و له أثثاره و مضاعفاته الاجتماعية و الاقتصادية و النفسية و الصحية ( ) .

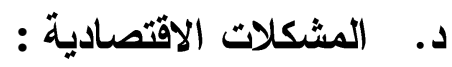

تثوقف مو اجهة المشكلات الاقتصادية علي الفرص المتاحة للشباب للعمل و الكسب كما تعتمد كذلك علي اتجاهاتهم نحو كيفية استغلال هذه الفرص ودو افع المبادرة من أجل السعي لتحسين المكانة الاقتصادية

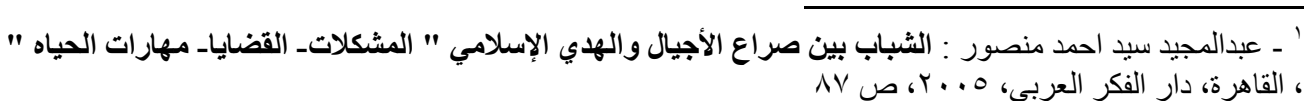




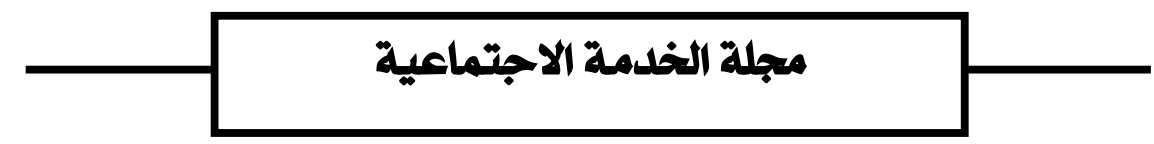

\section{هـ - مشكلة البطالة :}

تؤثر مشكلة البطالة سلبا علي الثباب العاطل وأسرته و المجتمع ككل وتقلل من نسبة وحجم القوة العاملة للمجتمع.

\section{و - التناقض بين القيم والمجتمع :}

من المعروف أن غرس القيم يبدأ في الأسرة في مرحلة الطفولة أو بمعني أخر أن التشئة الاجتماعية تبدأ في غرس القيم في الأطفال منذ مرحلة المهد بجانب ما تقوم

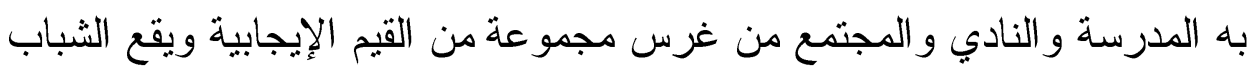

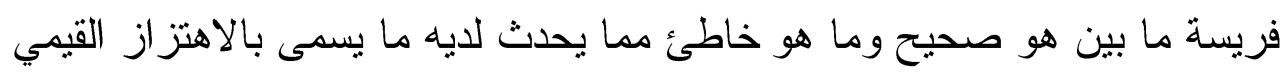

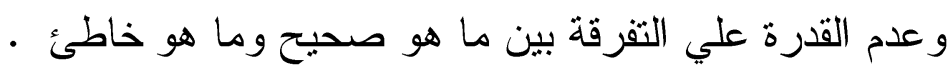

ثالثاً : خدمات الرعاية الاجتماعية المقدمة للشباب الجامعي :

يقصد برعاية الثباب بانها مجمو عه من الخدمات التي تقدم للشباب عن طريق

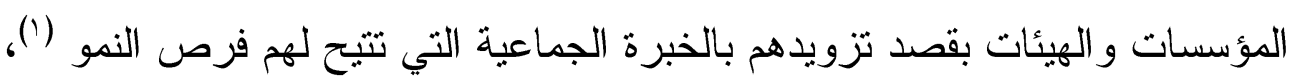
وتعرف أيضاً رعاية الثباب علي أنها توفير كل ما يمكن للشباب من تتمية قدر اته البدنبة و الفكرية و النفسية و الاجتماعية ليصبحو ا مو اطنين قادرين علي الإسهام بفاعلية

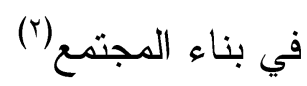

وتعرف أنشطة رعاية الشباب بانها المفهوم الذي يحتوي علي أوجه النشاط المختلفة و العلاقات و التفاعلات و الخبر ات للفرد و الجماعة التي توضع وتتفذ بمعرفة الأعضاء وبمساعدة الأخصائي لمقابلة حاجاتهم و إثباع رغباتهم (r).

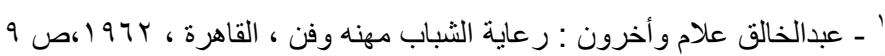

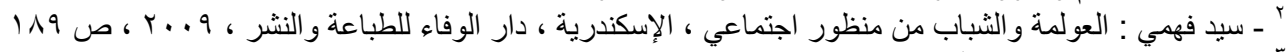

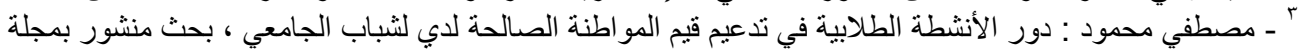

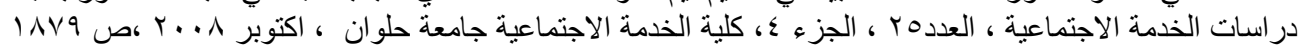




\section{مجلة الخدمة الاجتماعية}

أما عن خدمات الرعاية الاجتماعية للشباب الجامعي فهي كل ما تقوم به الجامعات بتوفير خدمات رعاية الطلاب سواء من خلال اشتر اكهم في لجان اتحاد الطلاب و الأسر الطلابية ذلك النوع من الخدمات تتمي من خلال مو اهب الثباب عن طريق اكتشاف المو اهب الثقافية و الفنية و الرياضية و الرحلات و المعسكر ات وذلك من خلال

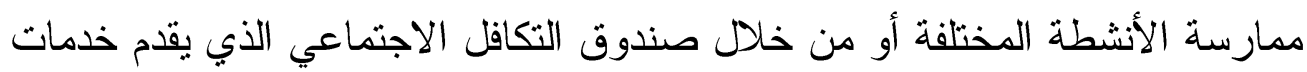
مادية للطلاب المحتاجين لها وسيتم توضيح ذلك كالاتي : 1- أنشطة رعاية الطلاب :

وتتمثل أنشطة رعاية الثباب الجامعي في الاتي في (') :

أ. النشاط الرياضي : يعمل النشاط الرياضي علي إتاحة الفرصة لممارسة

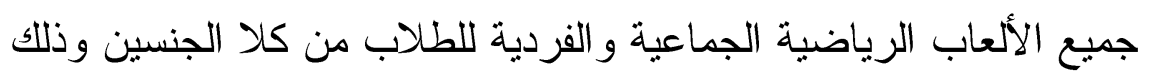
من خلال تكوين الفرق التي تمثل الكليات علي مستوي الجامعة و الجامعات

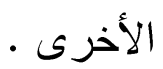

أ. النشاط الاجتماعي : ويقوم هذا النشاط علي تتظيم الرحلات بمختلف أنواعها بالإضافة إلى تتظيم الزيارات للمؤسسات الاجتماعية في المناسبات وكذلك هلك إقامة المسابقات في الموضوعات الاجتماعية . ب. النشاط الفني : ويقوم هذا النشاط علي اكتشاف وتتمية المواهب الفنية في كافة النواحي الفنبة كالغناء و العزف و التمثيل و الرسم والنحت و الأشغال

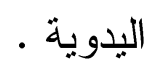

ج. النشاط الثقافي : ويقوم هذا النشاط بإتاحة الفرصة للطلاب بإظهار مواهبهم في الثعر والنثر والقصة القصيرة والمجلات الثقافية وحفظ القران

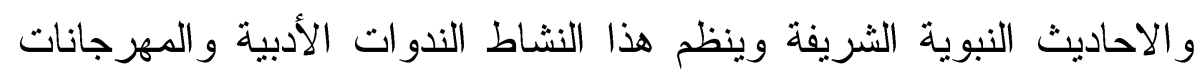




\section{مجلة الخدمة الاجتماعية}

الثقافية ويتيح الفرصة للاشترالك فيها بحضور أعلام الفكر والأدب في المجتمع.

هـ ـ نثاط الأسر الطلابية : ويهدف هذا النشاط لتنفيذ مجموعه من الأثشطة

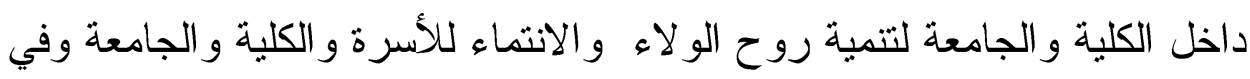
هذا النشاط يكون احد أعضاء هيئة التدريس بالكلية رائدا للأسرة وبمثابة قائد لها لها و. نشاط الجوالة والخدمة العامة : ويقوم هذا النشاط بتتفيذ العديد من المعسكرات و الأنشطة الفنية و الثقافية و إعداد فرق الجو الة و الذي يتمتعون فيه بممارسة حياة الخلاء ودر اسة الحركة الكثفية بشتي مر احلها وفيه يتعلم الطالب كيفية الاعتماد علي النفس وتقل الثخصية وزيادة خبر اته . ي. خدمات صندوق التكافل الاجتماعي : يقدم هذا الصندوق خدماته علي مستوي الكليات وتتمثل بعض من خدماته في الاتي : أ. يتم صرف الكتب الدراسية للطلبة غير القادرين علي شر ائها . ب. تقديم إعانات نقديه للطلاب بعد إجراء البحوث الاجتماعية لهم . ج. تخفيض رسوم الكلية لطلبة الانتساب أو الانتظام أو الإعفاء منها . د. دفع ثمن الأجهزة الطبية للطلاب المعاقين أو الإسهام في شر ائها . صرف إعانات للطلبة في حالة وفاة الو الد وكذلك صرف إعانات للأسرة في حالة وفاة الطالب وذلك في حالة الاستحقاق بعد إجراء البحوث الاجتماعية . 


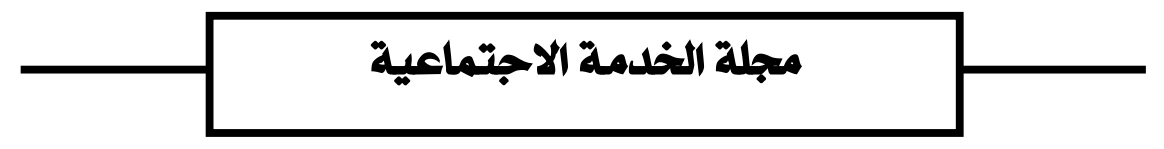

خامسًا: أبعاد وأدوات الجودة الشاملة: 1- أبعاد الجودة الشاملة:

تتحدد أبعاد الجودة الشاملة في النقاط التالية ('):

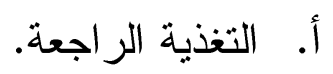

$$
\begin{aligned}
& \text { ب. تتمية العاملين وتحفيز هم . } \\
& \text { ج. اتخاذ القرار ات بناءاً على الحقائق. } \\
& \text { د - التزام الإدارة المستمر بالجودة. } \\
& \text { هـ ـ التركيز على احتياجات وتوقعات المستقيدين. } \\
& \text { و - فرق العمل من خلال العمل الجماعي . } \\
& \text { ز - النظرة المستقبلية، مفهوم الإدارة المنكاملة " . }
\end{aligned}
$$

ح - حدوث تحول في الطريقة التي تدار بها المؤسسة ، و التي تتضمن تركيز طاقات المؤسسة على التحسينات المستمرة لكل العمليات و الوظائف. r- أدوات تطبيق إدارة الجودة الثاملة في الجامعات :

إن من اهم أدوات إدارة الجودة الشاملة في الجامعات استخدام القائمة التالية(؟) : أ. التدريب و التعليم المستمر ب. التقييم الذاتي

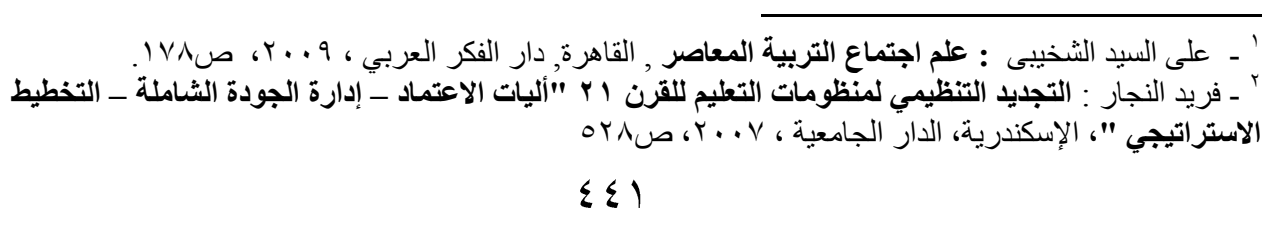




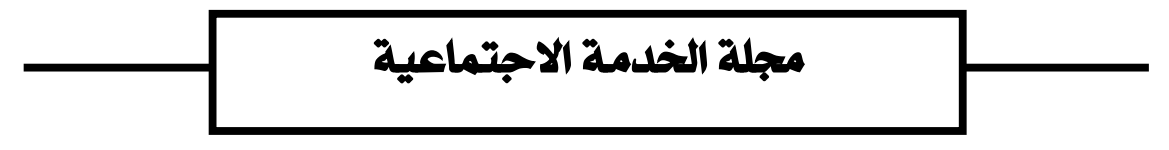

$$
\begin{aligned}
& \text { ج. التركيز علي خدمة المجتمع } \\
& \text { د. المشاركة في اتخاذ القرارات } \\
& \text { هـ - التجديد و التحسين المستمر } \\
& \text { و - إدارة العمليات و التحسينات } \\
& \text { ز - القيادة الديموقر اطية } \\
& \text { ح - التخطيط و التوجيه } \\
& \text { ط - التعاون بين القيادات وبين الكلبات } \\
& \text { 1 - متطلبات تطبيق إدارة الجودة الشاملة: }
\end{aligned}
$$

يمكن توضيح متطلبات تطبيق إدارة

$$
\begin{aligned}
& \text { الجودة الشاملة ف الآتي (1): } \\
& \text { أ. القيادة . } \\
& \text { ب. الالتز ام . } \\
& \text { ج. فرق العمل • } \\
& \text { د. التصميم الفعال . }
\end{aligned}
$$$$
\text { هـ - التركيز على العمليات . }
$$$$
\text { أ. ألقيادة : أل }
$$

' ـ محمد عبد الوهاب العزاوي : إدارة الجودة الثاملة ، الأردن ، دار اليازوري العلمية للنشر و التوزيع ، ه. . ؟، ص 


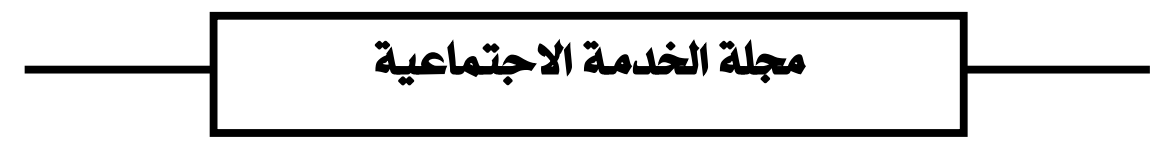

ان القيادة ، ضمن مفهوم إدارة الجودة الثاملة تعني القدرة على حث الأفر اد وتشجيعهم في أن تكون لايهم الرغبة والقدرة في إنجاز الأهداف.

ب. الالتز ام : إن التزام الإدارة العليا بإدارة الجودة الثاملة يتطلب من القادة التدرب على المفاهيم و المبادئ الأساسية لهذه الفلسفة بما يحقق الاستفادة من التادئ

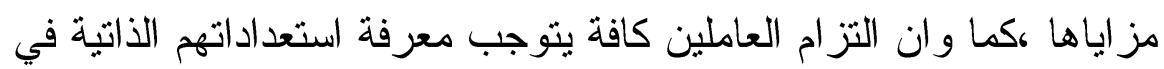
تقبل أنماط العمل الجديد و المركزة على الرقابة الذاتية للعمل .

ج. فرق العمل: إن العمل الجماعي هو أحد منطلبات نجاح إدارة الجودة الثاملة إذ تعد فرق العمل وسيلة مهمة لاندماج.

د. التصميم الفعال: تعد السلعة محور النشاط الذي يعكس الإمكانيات العملية

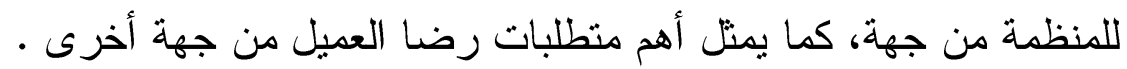

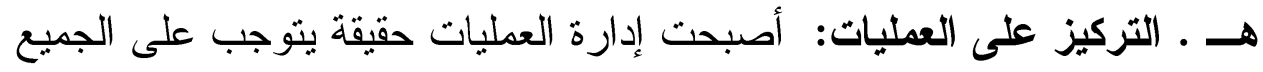
تفهمها أو إدر اكها كبعد أساسي لرضا العميل أو رفضه لهنتجات المنظمة، فإدارة العمليات الحديثة تتوجه نحو جعل مدر اء المنظمات هم مدر اء العمليات .

\section{قياس جودة خدمات الرعاية الاجتماعية :}

ليس هناك اتفاق علي تحديد معايير لقياس جودة الخدمات وفيما يلي استعر اض

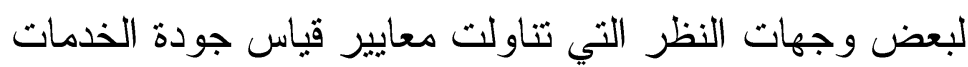

\section{-}

قام كثير من العلماء و الباحثين بدراسات متعددة تدور حول كيفية تقويم مستوى

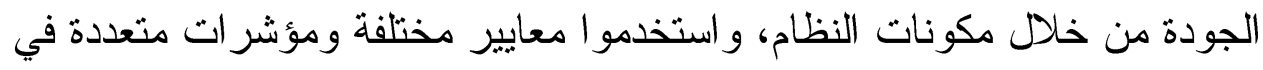
عملية التقويم ومنها على سبيل المثال ما قام به دونا بيدين من استخدام ثلاثة معايير 


\section{مجلة الخدمة الاجتماعية}

لتقويم مستوى الجودة هي (معيار الهيكل التنظيمي ومعيار العمليات الداخلية

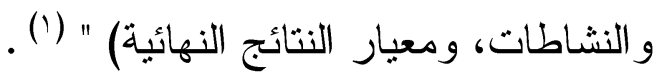

$$
\text { 1- معايير كروسبي: }
$$

حدد فليب كروسبي أحد مستشاري الجودة على المستوى العالمي أربعة معايير لضمان الجودة الشاملة تم تأسيسها وفقاً لمبادئ إدارة الجودة الشاملة (T.Q.M)

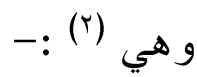

أ. التكيف مع منطلبات الجودة من خلال وضع تعريف محدد وو اضح ومنسق للجودة.

ب. وصف نظام تحقيق الجودة على أنه الوقاية من الأخطاء بمنع حدوثها من خلال

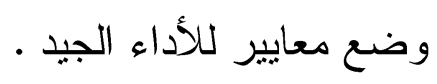

ج. منع حدوث الأخطاء من خلال ضمان الأداء الصحيح من المرة الأولى. د. تقويم الجودة من خلال قياس دقيق بناءً على المعايير الموضوعية والكيفية و الكمبة.

\section{1- نموذج سير فكوال (SERVQUAL):}

بدأت أبحاث الثلاثي الأمريكي بيري، زي ثامل وبار اشورمان بدر اسة مشهورة لبحث مكونات جودة الخدمة ووضع نموذج لها. من مجموعات النقاش خرج الباحثون بعشر معايير للجودة، تشمل كل عناصر الجودة في قطاعات خدمة المستهلك أو العملاء حسب رأيهر، وإن اختلفت أهمية كل معيار من قطاع لآخر وتتمثل هذه المعايير في ('):

1 - bedian A Dona.: Twenty years of research on the Quality of medical Care, Evaluation and the Health professions. vol. (8), no. (3). 1985 pp.253-254.

2 - Suarez J Gerald : three experts on quality management Phillip b Crosby, W

Eduard Deming, Joseph m Juran ,tqlo publication no 90-02, 1992, p.5 . 


\section{مجلة الخدمة الاجتماعية}

1- الاعتمادية: وتعني أداء الخدمة بدون خطأ من المرة الأولى، الوفاء بالالتز امات، صحة السجلات، صحة الفواتير، و التزام الوقت المحدد. ץ- الاستجابة: وتعني رغبة أو استعداد العاملين لخدمة الزبون وتقديم الخدمة ولتهات بسر عة.

س- الكفاءة: وتعني امتلاك المعرفة و المهارة من قبل العاملين الذين يظهرون للزبائن.

ع- سهولة وسرعة الوصول للخدمة: تسهيل الخدمة بالهاتف، قلة الانتظار، ملائمة توقيت وموقع الخدمة.

0- المجاملة: وتشمل و الاحترام للشخص، و لأدب و البشاشة في الاتصال الشخصي، ومظهر العاملين.

؟- الاتصال: وتشمل إعلام المستخدم عن الخدمة وتكلفتها، باستمرار وبلغة مفهومة، وطمأنته على حل المشاكل

V- المصداقية: وتشمل النزاهة و الثقة، و الحرص على مصلحة الزبون، ونتأتى أساسا من اسم الشركة وسمعتها، ومن طريقة التفاعل الشخصي مع الزبون. 1- الأمن: وتشمل الأمن من المخاطر و الثكك وضمان سرية بيانات الزبون. 9- فهم الزبون: وتشمل بذل الجهد لفهم الزبون؛ حاجاته ورغباته، و إعطائه عناية شخصية. • 1- الجوانب الملموسة في الخدمة: وتشمل المعدات والأدوات المستخدمة في تقديم الخدمة ومظهر العاملين. البعدين الأخيرين (الضمان و التعاطف) يحتويان بنودا تمثل في الأصل سبعا من المكونـات العشـر الأصـلية فالضـمان يتضـمن ( الاتصـال، المصـداقية، الأمـان، بينمـا يتضمن التعاطف (الكفاءة، المجاملة، فهم ومعرفة الزبون، والوصـول للخدمـة) و التي لم تبقي منفصلة بعد مر احل التدقيق المتعددة .

\footnotetext{
${ }^{1}$ - Parasuraman A., Zeithaml V.A. and Berry L.L: A conceptual model of service quality
} and its implication for future research. Journal of marketing, 1985, p 41-50. 


\section{مجلة الخدمة الاجتماعية}

وتؤكد الفكرة الأساسية للنموذج علي أهمية دور المستهلك وتجاوبه في تحقيق جـودة الخدمة، و أهمية تحقيق توقعاته، لكسب رضاه وو لائه .من هذا المنطلق، تأتي أهمية أن

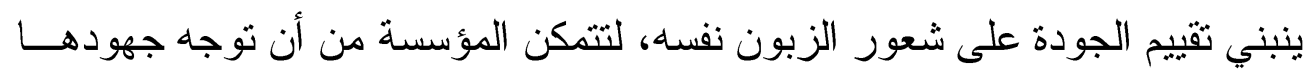

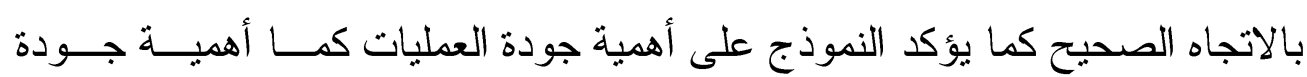

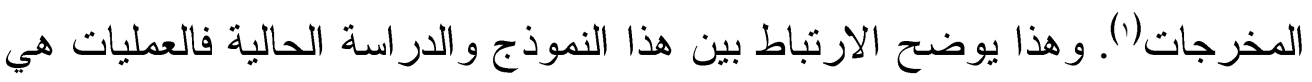
محور إعادة الهندسة ـ وقياس الجودة من وجهة نظر العملاء هو خطوة أساسية في أي لأي عملية جادة للتحسين، فبذلك يمكن ثوجيه الجهود لما يحقق رضا وو لاء العملاء (؟).

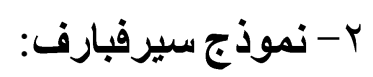

لعل كرونين وتايلور هما أبرز من انتقد اتخاذ التوقعات معيار القياس الجودة، مقترحين

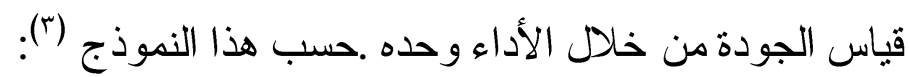
الجودة = الأداء يقصد بالجودة هنا، الجودة المدركة، ويقصد بالأداء الأداء الفعلي الذي يدركه الزبون، وهو نفسه المفهوم الذي يقيسه مقياس سير فكو ال مع التوقعات، لكن نموذج سيرفبارف لا يعتمد على التوقعات في حساب الجودة المدركة. وقد اقترح كرونين وتايلور نموذجهم البديل في مقالة لهما سنة ؛99 199 ، شملت قطاعات خدمية

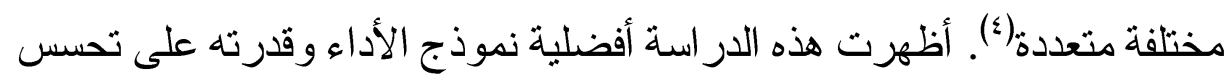

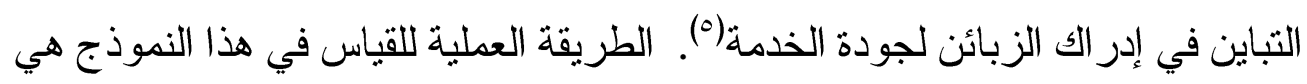
استخدام نفس أداة سيرفكو ال ، لكن مع الاستغناء عن البنود الاثثين و عشرين التي تقيس التوقعات يسمح هذا بلا شك بتسهيل لعملية القياس .هذا النموذج أيضا وردت الئس عليه

1 - Parasuraman A., Zeithaml Valarie A., Berry Leonard L:(1988). Op. cit.

2 - Sheel B. Sachdev, Harch V: importance of service quality dimensions, a multispectral study, Journal of Service Research, vol 4, 2004, p 97

3 - Cronin, J. J. \& Taylor, S. A:. Measuring Service Quality: a Re-examination and Extension. Journal of Marketing, vol 56, July 1992 ,p 55:68

4 - Cronin, J. J. \& Taylor, S. A. : Servperf Versus Servqual: Reconciling Performance-based and Perception-minus-expectations Measurement of Service Quality. Journal of Marketing, vol 58(1), 1994, p 125-131.

5 - Brady, M. K. et al: Performance-only Measurement of Service Quality a Replication and Extension. Journal of Business Research, vol 55, 2002, p 17-31. 


\section{مجلة الخدمة الاجتماعية}

تحفظات من البعض وتأيبدا من البعض الآخر ، ومنهم زيثامل نفسه، أحد بناة نموذج

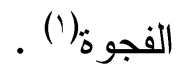

\section{- مزايا قياس جودة خدمات الرعاية الاجتماعية :}

تتيح عمليه قياس الجودة العديد من المزايا للمنظمات الخدمية لعل أهمها (؟): () معرفه ما يحتاجه العملاء وما اذا كانت الإجر اءات التي تتخذها المنظمة ملائمه

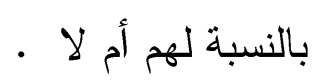

r) معرفه الأفر اد ذوي معدلات الأداء المرتفع و ذوي الأداء المنخفض وذلك حتى داء

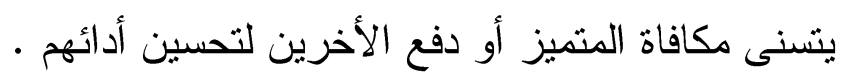

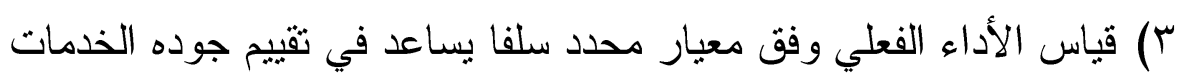

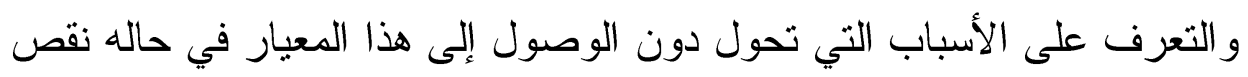

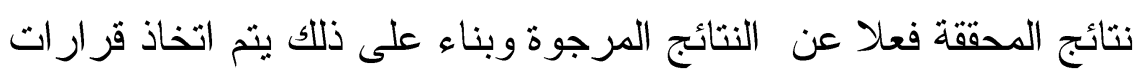
التغيير والتطوير اللازمة لحسن استخدام الموارد المتاحة و تحقيق اقصى عائد للخدمة باقل تكلفه.

ع) تحديد ما هو جيد وما هو سيء في ما يخص كل من المنظمة الخدمية وعملائها مما يساعد على الوصول التوازن بين مصالح كل من الطرفين لتحقيق التحسين

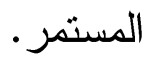

${ }^{1}$-4Cronin, J. J. and Taylor, S.A., (1994). Ibid.

2 - Whitely, R. C:the customer driven company , Addison Wesley Publishing co ,inc , 1995 


\section{مجلة الخدمة الاجتماعية}

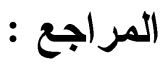

() احمد زكي بدوي : معم مصطلحات العلوم الاجتماعية، بيروت، مكتبه لبنان ،

$$
1919
$$

r) الادارة العامة لرعاية الثباب ، جامعة حلوان / تم الاطلاع بتاريخ

$$
r+1 V / 1 r / r_{0}
$$

r) أمجد قاسم : الجودة الثاملة في التعليم - تعريفها ,أهميتها , مبادئها وأهدافها ،

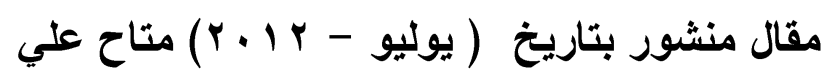

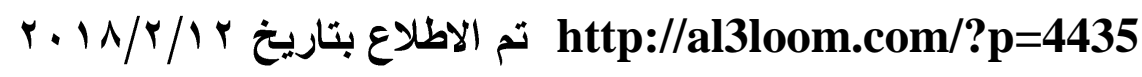
ع) خليل درويش ,وائل مسعود : مدخل إلى الخدمة الاجتماعية , القاهرة , الثركة

العربية المتحدة للتسويق والتوريدات , ^ . . ب سهير مصطفي :الخدمة الاجتماعية المهنية ورعاية الثباب ،بورسعيد ،مكتبة الجلاء الحديثة , . . . r، سيد فهمي : العولمة والثباب من منظور اجتماعي ، الإسكندرية ، دار الوفاء

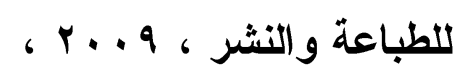

•) زين الدين أبو عبد الله الرازي: المحقق يوسف محمد, مختار الصحاح الجزء الأول, المكتبة العصرية - الدار النموذجية ، 1999 19. 7) العيد سلامة الخميسي: " قراعات في الإدارة المدرسية" , الإسكندرية, دار وفاء

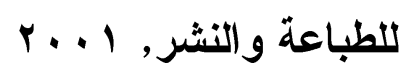

V عبدالخالق علام وأخرون : رعاية الثباب مهنه وفن ، القاهرة ، r 9 ا،عبدالمجيد سيد احمد منصور : الثباب بين صراع الأجيال والهاي الإسلامي " المشكلات- القضايا- مهارات الحياه " ، القاهرة، دار الفكر العربي، 


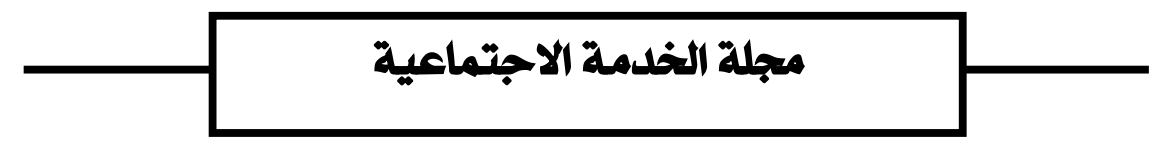

ه. . بعزت حجازي : الشباب العربي ومشكلاته ، الكويت ، عالم المعرفة ،

1910

^) على السيد الثخيبى : علم اجتماع التربية المعاصر , القاهرة, دار الفكر العربي $.1 \vee \wedge / 4.96$

9) علي حلمي : دور الثباب في التنمية الاجتماعية أو الاقتصادية، القاهرة ، مكتبة الأنجلو المصرية ، 1999

• (1) مريد التجار : التجديد التظظيمي لمنظومات التعليم للقرن اب "أليات الاعتماد - إدارة الجودة الشاملة - التخطيط الاستر اتيجي "، الإسكندرية، الدار الجامعية ، V V . . V قاسم نايف علوان : إدارة الجودة الثاملة ومتطلبات الأيزو، ليبيا، دار

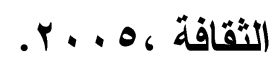

كليب الجهني المحدث: السيوطي ،المصدر الجامع الصغير, الصفحة أو

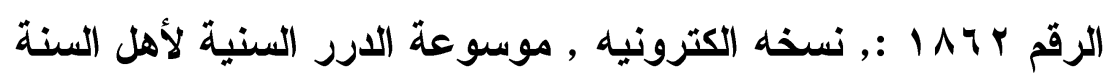
كلير فهيم : طريق نجاح الثباب في الحياة ،القاهرة، مكتبة الأنجلو

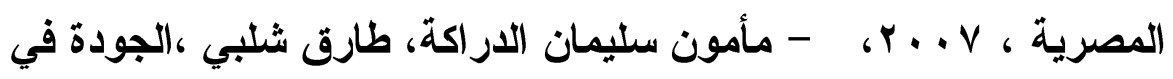
المنظمات الحديثة ، دار صفاء للنشر و التوزيع ، ، الأردن r . .. r، ، محمد السيد حسونة ,وأخرون: "مداخل الإصلاح المتمركز علي المدرسة في ضوء متطلبات تحقيق الجودة", المركز القومي للبحوث التربوية والتنمية,

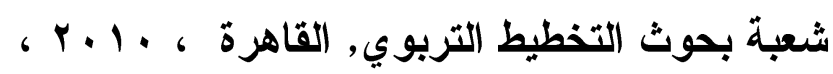
محمد بن شحات الخطيب نحو هيئة وطنية للاعتماد الأكاديمي للتعليم العالي في المملكة العربية السعودية، الرياض: مركز البحوث التربوية بكلية التربية،

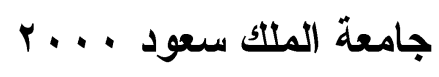




\section{مجلة الخدمة الاجتماعية}

محمد بن محمد بن المرتضس الزبيدي ، تاج العروس من جواهر القاموس

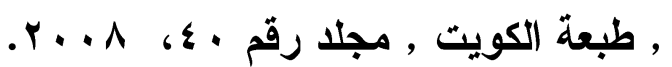

محمد شمس الدين احمد : الإثر اف في العمل مع الجامعات ،القاهرة

1919، ، المطبعة العالمية

مدحت محمد ابوالنصر : أساسيات إدارة الجودة الشاملة ، القاهرة ، دار

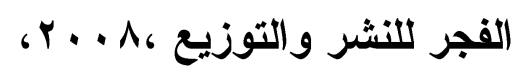

محمد عبد الوهاب العزاوي : إدارة الجودة الشاملة ، الأردن ، دار

$$
\text { اليازوري العلمية للنشر والتوزيع ، ه . . ب، }
$$

محمد عبدالغني : مهارات ادارة الاداء ، معايير وتطبيقات ادارة الجودة في

الاداء ،القاهره، مركز تطوير الاداء والتنمية ،999

• • مصطفي محمود : دور الأشطة الطلابية في تدعيم قيم المواطنة الصالحة لاي لشباب الجامعي ، بحث منشور بمجلة دراسات الخدمة الاجتماعية ، العدده r

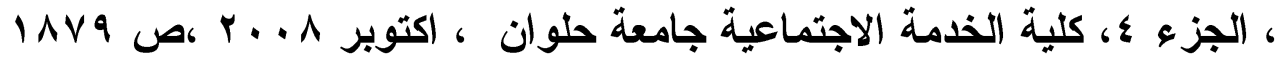

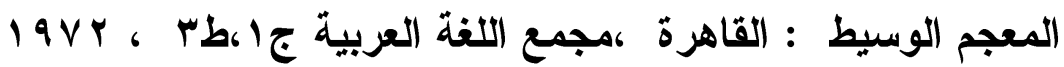

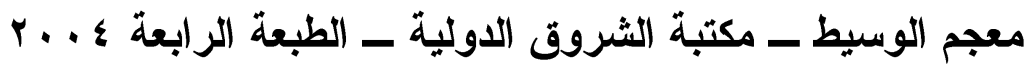

منى خزام: العولمة والسياسة الاجتماعية, الإسكندرية ، المكتب الجامعي

Oxford, Learners Pocket, Dictionary, 4th ED, 2008, bedian A Dona.: Twenty years of research on the

Quality of medical Care, Evaluation and the Health professions. vol. (8), no. (3). 1985

26) bikpen Doulas: community organization theory and practice, new jersey, prentice hill, Brady, M. K. et al: 


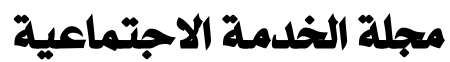

Performance-only Measurement of Service Quality a Replication and Extension. Journal of Business Research, vol 55, 2002,

27) Cronin, J. J. \& Taylor, S. A. : Servperf Versus Servqual:

Reconciling Performance-based and Perception-minusexpectations Measurement of Service Quality. Journal of Marketing, vol 58(1), 1994,

Cronin, J. J. \& Taylor, S. A:. Measuring Service Quality: a Re-examination and Extension. Journal of Marketing, vol 56, July 1992

29) Harvey L. and Green D:( Defining quality. Assessment and Evaluation in Higher Education, vol, 18. 1993, Oxford, 30) Parasuraman A., ZeithamI V.A. and Berry L.L: A conceptual model of service quality and its implication for future research. Journal of marketing , 1985,

31) Ruth Edunkle : Protective for children, encolopedia of social work, N.Y, National association of social workers, 1981,

32) Sheel B. Sachdev, Harch V: importance of service quality dimensions, a multispectral study, Journal of Service Research, vol 4, 2004,

33) Suarez J Gerald : three experts on quality management Phillip b Crosby, W Eduard Deming, Joseph m Juran ,tqlo publication no 90-02, 1992,

34) Webster's : world dictionary of American language ,N.Y, the world company, 1999,

35) Whitely, R. C:the customer driven company , Addison Wesley Publishing co ,inc , 1995 